\title{
FÃS DE CANAIS FEMININOS: DÁDIVA E AMBIGUIDADE NO YOUTUBE
}

\author{
PAULA CORUJA \\ UNIVERSIDADE FEDERAL DO RIO GRANDE DO SUL \\ PORTO ALEGRE, RIO GRANDE DO SUL, BRASIL \\ PAULA.CORUJA@GMAIL.COM
}

HTTP://DX.DOI.ORG/10.5902/2316882X23247 
FÃS DE CANAIS FEMININOS: DÁDIVA E AMBIGUIDADE NO YOUTU$B E$

Resumo: Este artigo é uma reflexão sobre aspectos particulares do fandom de youtubers e quais os sentidos que o dom adquire através das dinâmicas e práticas culturais dessas comunidades. Queremos demonstrar como o dom é um termo central dentro das dinâmicas observadas nos canais de fãs e nas disputas presentes nas caixas de comentários dos vídeos postados pela youtuber. Da mesma forma, mostrar sua polissemia através dessas mesmas dinâmicas.

Palavras-chaves: dádiva, YouTube, estudo de fãs, 5incominutos, fandom

\section{FANS DE CANALES FEMENINOS: DONACIÓN Y AMBIGÜEDAD EN YOUTUBE}

Resumen: Este artículo es una reflexión sobre los aspectos particulares de los fanaticos por youtubers y que detecta los significados que lo don adquiere a través de las prácticas dinámicas y culturales de estas comunidades. Queremos demostrar cómo el don es un término central en la dinámica observada en los canales e esas controversias en los cuadros de comentarios de videos publicados por youtubers. Del mismo modo, mostrar su polisemia a través de estas mismas dinámicas.

Palabras clave: don, YouTube, estudios de aficionados, 5incominutos, fandom.

FEMALE CHANNEL FANS: DONATION AND AMBIGUITY ON YOUTU$B E$

Abstract: This article reflects on particular aspects of fandom youtubers and which senses that the gift get through the dynamic and cultural practices of these communities. It aims to demonstrate how the gift is a central term in the dynamics observed in fans channels and the disputes in the comment boxes of videos posted by the youtuber. Similarly, shows their polysemy through those same dynamics.

Keywords: gift, YouTube, fan studies, 5incominutos, fandom.

Rev.Cad.Comun. Santa Maria, v.21, n.2, art 4, p. 68 de 91, maio/ago.2017 


\section{INTRODUÇÃO}

Esse trabalho é uma reflexão sobre aspectos particulares do fandom de youtubers e quais os sentidos que o dom - seja ele como característica desses personagens, ou sua circulação através da comunidade de fãs adquire através das dinâmicas e práticas culturais dessas comunidades. $O$ termo youtuber é usado para designar pessoas que produzem e compartilham vídeos através do YouTube, site de rede social, fora das estruturas da indústria midiática e/ou de entretenimento. Esses vídeos se encaixam no que é chamado de vlog (vídeo blog) em canais que podem ter foco o compartilhamento de informações, opiniões, tutoriais sobre um assunto específico (videogames, por exemplo), ou confessionais, ao estilo dos blogs escritos (Primo, 2008).

O primeiro aspecto que procuramos ressaltar são as particularidades do YouTube como site de rede social, que tem no conteúdo - os vídeos - o principal elo entre os usuários. Além disso, é um ambiente que, apesar do desenvolvimento da ferramenta ter tido a intenção de estimular a participação individual, foi subvertida pelos usuários e propicia a formação de comunidades'.

Outro aspecto importante que vamos destacar é o quanto o YouTube foi apropriado por mulheres, que são maioria hoje no tipo de vídeo que estamos nos concentrando (os pessoais). Além disso, elas interagem e produzem conteúdo com mais frequência dentro da plataforma. Isso reflete uma prática de transmissão de vídeos, que já era adotada na década de 1990 também por mulheres, com as possibilidades da banda da época. Espaço em que elas também são a maioria assediada e perseguida por haters.

Utilizamos um canal específico, o 5incominutos, para mostrar os sentidos que o dom adquire através das práticas dos fãs de Kéfera Buchmann, criadora do canal. Queremos demonstrar como o dom é um termo central dentro das dinâmicas observadas nos canais de fãs e nas disputas presentes nas caixas de comentários dos vídeos postados por Kéfera. Da mesma forma, mostrar sua polissemia através dessas mesmas dinâmicas. Existem muitas disputas dentro do fandom, inclusive a discussão sobre a legitimi-

1 Não é incomum ouvirmos falar em "comunidade do YouTube", tanto que o próprio Google, empresa proprietária desse site de rede social, criou o item "Comunidade" na atualização de 2014 para estimular a prática dentro da plataforma

Rev.Cad.Comun. Santa Maria, v.21, n.2, art 4, p. 69 de 91, maio/ago.2017 
dade dos fãs que fazem parte dessa comunidade, se os dons oferecidos por esses fãs são gratuitos, e o questionamento de se um fã que recebe, além de dádivas, dinheiro, por seu fanwork, ainda é um fã.

Além da reflexão, contamos com os dados e comentários dos vídeos do canal 5incominutos, observados (Angrosino, 2009, Braga, 2014, Fragoso et al, 2011) no período de 15 de setembro de 2015 a 15 de dezembro de 2015. Da mesma forma, o canal Frases de Kéfera, desenvolvido por uma fã, foi observado no mesmo período.

\section{CONHECENDO O YOUTUBE E OS YOUTUBERS}

É na combinação entre "cultura do quarto" e popularização do acesso midiático que conhecemos os Youtubers. Numa busca rápida pelo sistema da própria rede social pelo termo "Youtubers", temos mais de 148 mil resultados, o que demonstra a popularização da prática. Se a busca for por vlog, o resultado é ainda maior: 40,8 milhões de entradas. Esses personagens, que usam a estética da confissão para a câmera no quarto, abordam os mais diversos assuntos e aparecem com destaque nos rankings de popularidade da rede. E essa popularidade rende muito economicamente e já chama atenção dos grandes produtores. A Forbes, tradicional revista de economia estadunidense, divulgou a lista com os dez criadores de conteúdo do site mais bem pagos do mundo. Em primeiro lugar, com mais de 40 milhões de assinantes, o sueco Felix Kjellberg, que tem um canal sobre videogames e faturou US\$1 12 milhões no ano passado².

Essa tendência também acontece no Brasil. Um levantamento da Provokers Target ${ }^{3}$ aponta que no país existem, hoje, cerca de 70 milhões de espectadores de vídeos online e que o YouTube é a principal ferramenta de consumo de vídeos. Uma pesquisa da Ericsson aponta que esse site de rede social é responsável por $70 \%$ de todo o tráfego de vídeos do planeta

2 Disponível em http://revistapegn.globo.com/Banco-de-ideias/Mundo-digital/noticia/2015/10/empreendedores-faturam-alto-com-canais-no-youtube.html

Acesso em 5/12/2015

3 Disponível em http://www.dgabc.com.br/Noticia/1672951/youtube-a-brincadeira-que-virou-negocio Acesso em 5/12/2015

Rev.Cad.Comun. Santa Maria, v.21, n.2, art 4, p. 70 de 91, maio/ago.2017 
em redes móveis ${ }^{4}$. O YouTube é um site de rede social que agrega, principalmente, o público mais jovem. Essa é apenas uma das constatações da pesquisa Hábitos e Comportamento dos Usuários de Redes Sociais no Brasil, realizada pela empresa E. Life ${ }^{5}$ para entender o uso de internet, de redes sociais e como são utilizadas pelos brasileiros. Em 2014, 85,2\% dos respondentes apontou o YouTube como rede social mais acessada. Quando o recorte por idade é feito, o número é ainda maior: 98,7\% entre jovens até 19 anos usam o YouTube. O próprio Google, empresa proprietária do YouTube, já aposta em eventos off-line para suas "estrelas" on-line, que a exemplo do que acontece no resto do mundo, apresentam rendimentos mensais de até centenas de milhares de reais ao ano. Em outubro de 2015, em São Paulo, aconteceu a primeira edição do YouTube FanFest Brasil. 0 evento $^{6}$, que já teve edições em países como Índia, Canadá, Tailândia, Coreia do Sul, Austrália e Indonésia, reuniu "algumas das mais importantes estrelas do YouTube” do país, nas palavras da organização. E por estrelas, entendam-se esses produtores de conteúdo, que não raramente gravam e editam sozinhos os próprios vídeos para colocar na plataforma, e que contam com milhares - os mais populares, milhões - de assinantes nos canais.

Uma das principais características do YouTube, e que é tida como responsável pelo sucesso desse site de rede social, é que permite a recomendação dos vídeos, demarcar a apreciação ou não pelos usuários - através dos botões "curti" ou "não curti" - e os comentários. A caixa de comentários de cada vídeo, e dentro de cada canal, tem funcionado como espaço de interação - e disputas - dessa audiência, majoritariamente jovem. Uma audiência que nasce na cibercultura (Levy, 1999), e que usa todas as ferramentas disponíveis para se expressar. O YouTube, plataforma que foi desenvolvida para estimular a participação individual, teve sua lógica subvertida pelos sujeitos, que a transformaram para estimular a criatividade coletiva e articular um espírito de comunidade.

Diferente de outras redes sociais em que as associações são mais ób-

4 Disponível em http://exame.abril.com.br/tecnologia/noticias/youtube-e-responsavel-por-70-do-trafego-de-videos-em-redes Acesso em 5/12/2015

5 A pesquisa completa está disponível gratuitamente para download em https:// pt.slideshare.net/secret/BXWSFoYxOhas8X Acesso em 5/12/2015

6 Disponível em http://g1.globo.com/pop-arte/blog/quem-curte-o-blog-de-fa-clube/post/youtube-fanfest-brasil-celebridades-da-internet-tem-dia-de-popstar-em-sao-paulo.html Acesso em 5/12/2015

Rev.Cad.Comun. Santa Maria, v.21, n.2, art 4, p. 71 de 91, maio/ago.2017 
vias, ao adicionar "amigos", no YouTube é o vídeo que gera as maiores conexões sociais, e as "amizades" são substituídas pela possibilidade de acompanhar canais, através da opção "inscrever-se". Num estudo realizado por Burgess e Green (2008), a partir de uma pesquisa feita com 4.320 vídeos do YouTube, foi levantado que mais de dois terços desse conteúdo eram de vlogs, uma atividade que mobiliza, basicamente, conteúdo gerado por usuário (user-generated content, UGC, na sigla em inglês), se transformando em uma forma emblemática, mesmo que não seja nova, de participação no YouTube. Da mesma forma, os autores salientam que "o vlog, como gênero de comunicação, convida à crítica, ao debate e à discussão"” (Burgess e Green, 2008, p.7).

É importante salientar que nem todos que acessam o YouTube se engajam da mesma forma na plataforma. A fim de classificar essas práticas, Patricia Lange (2007) propôs cinco níveis de engajamento: a) antigos participantes, que já fizeram upload de vídeos, participaram das discussões, mas agora não são mais ativos; b) usuários casuais, que podem não ser cadastrados na rede, realizam buscas por vídeos específicos que desejam ver, ou que acessam através de links que Ihe foram enviados; c) participantes ativos, que possuem conta e, se não postam os próprios vídeos, assinam vários canais e participam das discussões, deixando comentários nos canais de outras pessoas; d) Youtubers, que têm mais envolvimento, de acordo com o tipo e volume de participação; e por último e) celebridades do YouTube, que também são identificados como Youtubers, mas que ultrapassam a barreira da rede, sendo conhecidos dentro e fora do YouTube, e possuem milhões de inscritos em seus canais. Mesmo que não sejam categorias definitivas, podem nos ajudar a visualizar o nível de envolvimento - determinado pelas práticas - que é possível ter com esse site de rede social. Em alguns outros estudos (Lange, 2008, Strangelove, 2011, Burgess e Green, 2008) vemos o quanto os sujeitos que se envolvem a ponto de comentar nos vídeos são ativos. Além disso, muitas vezes, o comentário serve como forma de chamar a atenção do dono ou dona do canal, tentando ter uma visibilidade social maior, principalmente ao obter resposta de uma celebridade do YouTube, por exemplo.

7 Tradução para "the vlog as a genre of communication invites critique, debate and discussion"

Rev.Cad.Comun. Santa Maria, v.21, n.2, art 4, p. 72 de 91, maio/ago.2017 


\subsection{PLATAFORMA DE EXPRESSÃO FEMININA}

Mesmo antes do YouTube, a transmissão de vídeos por pessoas comuns já acontecia. Theresa Senft (2008) conta em Camgirls ${ }^{8}$ a história desse produto audiovisual que surgiu nos anos 1990 com uma característica marcante: preponderantemente ligado ao universo feminino. Na época, câmeras eram adaptadas em computadores, não havia som e a conexão de internet discada permitia que uma nova imagem fosse enviada apenas a cada cinco minutos. A maioria das camgirls identificadas por Senft transmitia do próprio quarto, o que ela chamou de homecamming. Ao todo, a pesquisadora identificou cinco modalidades de homecamming: vida real, artística, pornô, grupo da casa e comunitária. Para entender melhor esse universo, Senft se tornou ela própria uma camgirl e passou a transmitir vídeos de seu quarto e a compartilhar com uma série de fãs.

A autenticidade, característica muitas vezes levantada para explicar o sucesso dos youtubers hoje (Strangelove, 2011), já era apontada por Senft (2008) para explicar a popularidade das camgirls. A pioneira delas, Jennifer Ringley, chegou a declarar em uma entrevista que queria "mostrar para as pessoas que aquilo que assistimos na TV - pessoas com cabelo perfeito, amigos perfeitos, vidas perfeitas - não é a realidade. Eu sou a realidade" (Senft, 2008, p.16), mostrando esse forte apelo ao que é real e autêntico. Claro que uma câmera no quarto não garante autenticidade, e os debates travados no meio acadêmico para determinar o que é autêntico - se é que existe uma autenticidade genuína - são praticamente intermináveis, porém é uma resposta constante da audiência a essa falta de recursos profissionais e produção fora da indústria de entretenimento.

Se na década de 1990 já eram as mulheres que dominavam os espaços de transmissão online amadora feita em ambientes domésticos, da mesma forma elas dominam os vlogs confessionais no YouTube. Um estudo realizado no Canadá sobre gênero no YouTube ${ }^{9}$ aponta que as mulheres

8 O termo se refere a como eram chamadas, na década de 1990, as garotas, a maioria adolescentes, que realizavam transmissões caseiras, muitas vezes dos próprios quartos.

$9 \quad$ Foi realizado um estudo, em outubro de 2006, conduzido pela pesquisadora canadense Heather Molyneaux (2008) para investigar como homens e mulheres se comunicavam usando vlogs no YouTube e como reagiam como audiência de vlogs. Foram coletados 1.028 vlogs, de língua inglesa, que revelaram aspectos interessantes de pro-

Rev.Cad.Comun. Santa Maria, v.21, n.2, art 4, p. 73 de 91, maio/ago.2017 
postam duas vezes mais vlogs que interagem com a comunidade do YouTube e têm mais acessos. Um dos pontos que os pesquisadores levantaram é que os vlogs que contém informações pessoais são o segundo tipo de vídeo mais assistido e, entre os produtores, $60 \%$ eram mulheres.

O YouTube tem se mostrado um espaço de desconstrução. Claro que encontramos muito conteúdo conservador e que dissemina preconceitos, mas o YouTube têm servido para dar voz e espaço de diálogo em torno de temas que não encontram outros espaços na meios convencionais. $O$ feminismo, e a questão da representação da mulher e problematização dos papéis de gênero, tem sido pautado permanentemente em vários países e em diversos idiomas. Se antes as vozes masculinas dominavam o ciberespaço (Primo, 2008), aos poucos as mulheres têm recorrido a ele como espaço de resistência de autorrepresentação. "Comunidades que estão lutando por representação e autoconfiança estão transformando o YouTube em um meio de adotar um contra-discurso aos preconceitos vigentes ${ }^{10 "}$ (Strangelove, 2011, p.95). Não só há um número significativo de Youtubers mulheres, mas de usuárias ativas, que se engajam nos debates que acontecem dentro desses canais.

Dentro desse espaço, e dos debates sobre gênero e feminismo, que se agora ganham um maior espaço midiático em programas de televisão"11 e revistas femininas ${ }^{12}$, que proclamavam uma feminilidade normativa, já

dução e recepção desse produto audiovisual por gênero.

10 Tradução para "Communities that are struggling for representation and self-confidence are turning YouTube as a means of enacting a conter-discourse to prevailing prejudices"

11 O Programa Esquenta, da apresentadora Regina Casé, dedicou o programa do dia 6/12/15 para falar sobre feminism. Disponível em http://gshow.globo.com/programas/esquenta/episodio/2015/12/06/esquenta-recebe-daniela-mercury-e-paula-fernandes.html Acessado em 25/01/16.

12 A tradicional revista Elle fez uma edição especial sobre feminino em dezembro de 2015. Quatro capas diferentes entraram em circulação com slogans como "Mexeu com uma, mexeu com todas", "Meu corpo, minhas regras", "Vestida ou pelada, quero ser respeitada", "Meu decote não te dá direitos" e "Minha roupa não é um convite". Além disso, trouxe um manifesto feminista assinado por blogueiras e mulheres que encabeçam organizações sem fins lucrativos feministas, além de entrevistas sobre o tema. Mais informações em http://ffw.com.br/noticias/moda/elle-faz-manifesto-feminista-em-capas-da-edicao-de-dezembro/ Acesso em 25/01/16.

Rev.Cad.Comun. Santa Maria, v.21, n.2, art 4, p. 74 de 91, maio/ago.2017 
estão em discussão (e sendo constantemente problematizados) em sites de redes sociais, como YouTube, e blogs há bastante tempo. Aqui no Brasil, alguns desses canais, inclusive, impulsionaram publicações e disputas, como é o caso do canal JoutJout Prazer, do YouTube ${ }^{13}$. E como uma observação rápida é capaz de demonstrar, essas mulheres que encabeçam essa problematização não saem ilesas: muitas delas são alvo de haters, como são chamados aqueles usuários que postam comentários com conteúdo agressivo e gratuito, sem uma justificativa ou argumentação em torno da crítica. E isso não é de hoje. Strangelove (2011) já apontava que "as muIheres do YouTube são assediadas, ridicularizadas, perseguidas e sujeitas a discursos violentos e vulgares" (p.98). Outros autores também apontam que são as mulheres os mais recorrentes alvos de haters no YouTube (Burgess e Green, 2008, Lange, 2007, Lange, 2008, Szostak, 2013).

\section{MAIS DO QUE 5INCOMINUTOS, O FANDOM DE KÉFERA}

O 5 incominutos foi criado por Kéfera Buchmann, de 22 anos, e já conta com 7.511.6314 inscritos e seus vídeos têm mais de 605 milhões de visualizações ${ }^{15}$ desde 2010, quando o canal foi criado. Entre os assuntos abordados regularmente está o que no senso comum é chamado de "universo feminino", principalmente sobre consumo e estilo de vida - e aí entra de tudo, de dietas frustradas a TPM, passando por flertes, bagunça, e até banheiro público. Com um público consolidado, cada vídeo conta mais de 2 mil comentários (alguns ultrapassam facilmente os 30 mil comentários), formando uma rede de fãs que aguarda - alguns com demonstração pública de ansiedade - os vídeos gravados toda a terça e sábado, além de um

13 Tantas disputas aconteceram nas redes sociais que o tema virou pauta na imprensa, como pode ser visto aqui, em que o jornal O Globo se refere à "guerra digital" travada em função do viés feminista de parte do conteúdo abordado pela Youtuber: http://oglobo.globo.com/sociedade/pagina-de-jout-jout-reativada-apos-guerra-digital-nao-vao-me-calar-17966462

14 Dado atualizado em 2 de fevereiro de 2016. Disponível em https://www.youtube. com/user/5incominutos

15 Dados fornecidos pelo YouTube, disponíveis em https://www.youtube.com/ user/5incominutos/about e coletados no dia 2/2/2016

Rev.Cad.Comun. Santa Maria, v.21, n.2, art 4, p. 75 de 91, maio/ago.2017 
streaming ao vivo por semana, sem data fixa. A motivação para criar o canal, conta ela, era para poder aparecer na TV. Na época com 17 anos, tendo recém terminado o Ensino Médio e com o sonho de ser atriz, resolveu gravar um primeiro vídeo para tentar ter alguma visibilidade. $O$ tema desse primeiro vídeo: a irritação com as vuvuzelas da Copa do Mundo de 2010. Desde então, ganhou milhares de fãs, que comentam entusiasticamente e a defendem de quem aparece na caixa de comentários com qualquer tipo de crítica. Hoje, além do canal, ela conta com uma loja online que vende produtos exclusivos e lançou o livro "Muito mais que Cinco Minutos", uma biografia, que já está entre os títulos mais vendidos ${ }^{16}$ do ano passado.

Observando o canal de Kéfera, foi possível ficar mais familiarizada com a sua audiência e entender como essas pessoas, cerca de 20\%, em média, do total de visualizações dos vídeos, se comportavam naquele ambiente, que pode ser considerado um espaço social (Hine, 2004). Um dos links que aparece constantemente nos comentários, com elogios da comunidade que acessa o canal de Kéfera, é do canal Frases da Kéfera. Karoline de Oliveira, 26 anos, que é fã declarada da Youtuber e do canal 5 incominutos, produz o canal em homenagem à Kefera Buchmann. Esse canal, um trabaIho de fã, já conta com mais de 200 mil assinantes, o que lhe rendeu um reconhecimento formal do Google ${ }^{17}$, empresa detentora do YouTube. Mas Karoline não está sozinha quando o assunto é a produção de fã sobre Kéfera. Um levantamento feito em três sites de rede social - YouTube, Twitter e Facebook - mostra que há mais de 10 canais, 50 perfis e 15 páginas e 100 grupos em homenagem à Kéfera. Onde é possível ter acesso à idade ${ }^{18}$ das pessoas que administram essas homenagens, a constatação é de que são adolescentes ou jovens adultos (entre 15 e 25 anos).

16 Como é possível ver aqui: http://entretenimento.uol.com.br/noticias/redacao/2015/09/08/milhares-de-fas-lotam-bienal-do-livro-para-ver-vlogger-kefera-buchmann.htm Acesso em 7/12/2015

17 Karoline ganhou uma placa do Google, empresa proprietária do YouTube, de reconhecimento como canal de fã de sucesso, pelos mais de 100 mil inscritos.

18 Esse é sempre um dado incerto em pesquisas na internet. A idade nesses perfis, quando fornecida, é autodeclarada, o que pode induzir ao erro. Para esse caso é feita uma observação maior, para procurar postagens em que há a declaração da idade, ou que leve para o perfil pessoal onde se tem acesso ao dado. A idade não é um fator determinante, mas complementar para se pensar esse fandom.

Rev.Cad.Comun. Santa Maria, v.21, n.2, art 4, p. 76 de 91, maio/ago.2017 


\subsection{O FANDOM DO YOUTUBE}

Como é notório, Fandom ${ }^{19}$ é o termo usado para designar o domínio dos fãs, falar de seu senso de comunidade, das ações e práticas. As ações de fãs, segundo Hills (2002), são sempre performáticas, como uma identidade que está sendo construída e que busca conexão através de um mesmo objeto/fonte de adoração. É importante lembrar que nem sempre aqueles que se reconhecem e se identificam como fãs realizam "trabalhos de fã", os chamados Fanworks. Aqui os mais conhecidos são as Fanfictions, reinterpretações de narrativas a partir da história de que se é fã, Fanvids, vídeos produzidos por fãs, Fanzines, publicações feitas e voltadas para os fãs, e Fanarts, todo o tipo de trabalho manual sobre o que é adorado (Amaral et al, 2014). Essa produção é essencialmente dadivosa, mas não se restringe a isso. Há um grande número de outros trabalhos criativos executados por fãs. Vemos ainda canais, páginas e perfis no Twitter que celebram a youtuber de quem são fãs, compartilham frases, trocar ideias com outros fãs e ainda elaboram memes ${ }^{20}$ com esses conteúdos para que sejam compartilhados entre a comunidade. O YouTube deixa, assim, de ser apenas uma plataforma onde os fãs de diversas narrativas ou personagens conhecidos através de meios de comunicação de massa postavam e compartilhavam seus trabalhos, para fazer emergir novos personagens também dignos de adoração e trabalho intenso de uma comunidade própria de fãs.

O fandom e suas práticas particulares são constantemente discutidos na academia, mas também são assunto dentro das comunidades de fãs. Podemos dizer, que se baseia em uma economia da dávida, em que os dons são oferecidos, recebidos e, também, trocados (Mauss, 2003). Os fãs produzem, disponibilizam para outros fãs, que se engajam nessas comunidades também partilhando algum tipo de fanwork. A reciprocidade desses dons pode ter um vasto número de formas tangíveis (através de outros tipos de fanwork) e intangíveis (pela atenção, reconhecimento e status dentro da comunidade). É através dessa troca de dons entre fãs que acontece a experiência do fandom como uma comunidade - ou uma série de

19 Fandom é a junção das palavras Fan, de fã, e Kingdom, que significa reino.

20 O termo meme é usado para descrever um conceito de imagem, vídeo e/ou relacionados ao humor, que se espalha via internet. O termo é uma referência ao conceito de memes, desenvolvido por Richard Dawkins, em 1976.

Rev.Cad.Comun. Santa Maria, v.21, n.2, art 4, p. 77 de 91, maio/ago.2017 
comunidades - mais do que um grupo de pessoas aleatório.

Outro ponto importante é entender o fandom não só como um sistema de reciprocidade dos dons, mas de circulação dos dons, o que transforma, também, esse em um espaço de disputas e avaliação constante da atividade e engajamento dos fãs. Muito da experiência que é possível ter do fandom, incluindo o reconhecimento dele como comunidade (Fiske, 1992), vem através do trabalho do outro, da oferta do outro. Dentro da academia, e do próprio fandom, há uma tendência a apenas reconhecer, estudar e discutir os dons mais tradicionais dos fãs, como as fanfictions e fanarts, mas o que surge de trabalhos criativos, como no canal em homenagem à Kéfera, começam a ganhar atenção, não só pelo reconhecimento pelo trabalho de fã, mas mesmo pelo questionamento sobre qual é o limite, a barreira e a validade do trabalho do fã como uma dádiva gratuita. Também no fandom, o dom é ambíguo (Chanial, 2009).

\subsection{A CIRCULAÇÃO DE DONS DOS FÃS DE (PARA) KÉFERA}

Para começar a compreender melhor o fandom de Kéfera, começamos a observar as postagens da youtuber e, no momento em que ouvimos falar do canal dedicado à ela pela fã, passamos a observá-lo também. O YouTube, como mostramos anteriormente, tem certas especificidades como site de rede social. A associação entre as pessoas não vem do "pedido de amizade", que cria um duplo elo entre os usuários, mas do ato de "inscrever-se", que cria um elo unilateral. Antes era possível ter os dois: os elos duplos, de "amizade", e as inscrições. Ao longo dos pouco mais de 10 anos do lançamento da plataforma, algumas outras mudanças foram importantes para entender a dinâmica atual dessa rede. As caixas de comentários foram privilegiadas como o espaço de conversação e diálogo. Há uma cobrança da comunidade do YouTube para que as caixas de comentários sejam deixadas sempre abertas, sem moderação prévia, o que configuraria o diálogo franco, em que as críticas são recebidas e podem ser respondidas. Isso gerou um certo ponto de conflito por causa dos haters, mas a avaliação geral é que é melhor lidar com os haters do que não poder contar com um espaço sem censura (Lange, 2008). A partir de 2013, a função "Responder com vídeo" foi desativada. Com ela, a partir de um clique era possível gravar o vídeo usado como resposta. O YouTube alegou que era uma função pouco usada. Para responder com um vídeo, hoje, é

Rev.Cad.Comun. Santa Maria, v.21, n.2, art 4, p. 78 de 91, maio/ago.2017 
preciso gravar o vídeo, fazer o upload na ferramenta e colar o link gerado no espaço do comentário, o que não garante que a pessoa assista.

Dessa forma, passamos a observar os vídeos postados e as dinâmicas que eram desenvolvidas nas caixas de comentários, tanto da Youtuber, como do canal feito em homenagem a ela. Tentamos o contato com a fã destacada para, ao conversar com ela, entender as motivações, os processos e o próprio entendimento dela sobre a atividade de fã desenvolvida. Porém, após algumas conversas informais, ela declinou o convite e continuamos apenas com o trabalho de observação dos dois canais ${ }^{21}$.

Durante as observações nas caixas de comentários dos dois canais, vimos que os fãs consideram Kéfera (e outros youtubers) muito mais influentes que qualquer figura televisiva, já que identifica uma sinceridade maior no jeito e nos motivos de estar ligando uma câmera dentro da própria casa para essa conversa, que resultam nos vídeos postados. Algumas fãs disseram que Kéfera traz sinceridade e consegue compreender o que elas querem dizer. Outros destacam que a sinceridade vem do jeito escrachado de falar, "sem papas na língua". Outras qualidades atribuídas pelos fãs são determinantes: inteligência, bom humor (consideram-na engraçada no jeito de se expressar) e sagacidade. Apesar de gostarem muito da youtuber, muitas vezes faltam os termos para definir porque gostam dela e repetem, diversas vezes, que Kéfera é diferente. Isso transforma o canal 5incominutos em um ponto de encontro, onde encontram sua youtuber favorita e podem conversar com outras pessoas que também compartiIham da adoração por Kéfera.

Aqui notamos mais uma faceta do dom: os fãs atribuem aos youtubers a existência de um dom no sentido da dádiva ${ }^{22}$. São pessoas especiais, destacadas, que sabem se comunicar, são sinceros, bem humorados e inteligentes. Quando os fãs perdem as palavras e resumem dizendo que Kéfera é diferente, no sentido de que ela tem algo especial que não conseguem definir, falam do dom atribuído a Kéfera. “(...) o dom é, fundamentalmente, um termo que preenche um espaço que deveria ser ocupado por outro

21 Karoline concedeu uma entrevista ao jornal Zero Hora (publicada na edição do dia 1 de novembro de 2015) e algumas das informações e opiniões emitidas por ela à publicação também são mencionadas.

22 "o dom só existe quando há um público que o reconheça como tal" (Damo, 2010, p.192)

Rev.Cad.Comun. Santa Maria, v.21, n.2, art 4, p. 79 de 91, maio/ago.2017 
termo, mas que não está disponível” (Damo, 2007, p.199).

Para essas pessoas que os especialistas definem como comuns, mas que os fãs reconhecem como "especiais" e "diferentes" que estão sendo produzidos fanworks, uma dádiva que oferecem ao ídolo como resposta à dádiva que recebem a cada novo vídeo postado no YouTube. Aqui, podemos chamar atenção para dois pontos. Em primeiro lugar, o dom - esse produzido pelos fãs - tem função de elo (Caillé, 2006), entre os fãs, que formam comunidades destinadas à adoração à youtuber; e entre a youtuber e os fãs, que identificam nela um dom que vale a pena ser destacado. Em segundo lugar, nessa produção para dentro do fandom e do fandom para a youtuber, é possível visualizar a circulação do dom, "suscitando uma cadeia de trocas que, por seu turno, implicam a sua reconversão incessante, na forma de dinheiro e afeto" (Damo, 2007, p.194). Vale lembrar, nesse momento, algo que destacamos no início do texto: youtubers como a Kéfera têm rendimentos na casa dos seis dígitos apenas pela visualização dos vídeos no YouTube, sem contar o quanto lucram em posts patrocinados e campanhas publicitárias. Quanto mais os fãs procuram por ela e visualizam seus vídeos na plataforma, mais ela ganha em afeto e em dinheiro. Diferente do futebol, em que o dom precisa ser identificado, conhecido, lapidado e comercializado para se converter em dinheiro (Damos, 2007), os youtubers dependem basicamente dos fãs para ter sucesso financeiro. Quanto maior e mais ativa a comunidade de fãs de um youtuber, mais isso rende em dinheiro.

Diferente de outras comunidades de fãs que atuam na internet, que possuem fóruns específicos e, muitas vezes, fechados (Jenkins, 2009), os sujeitos que identificamos como fãs de youtubers usam essencialmente ambientes abertos de sites de redes sociais para conversar, compartilhar opiniões e parte do trabalho criativo em homenagem ao ídolo. Essa dinâmica abre espaço para que pessoas que não sejam identificadas como fãs observem, participem e, também, critiquem.

Nesse ponto, parece importante destacar uma questão-chave trabaIhada por Godbout (2002), a liberdade do dom. Essa liberdade tem base na relação de confiança, um tipo de confiança que se estabelece como princípio dentro das comunidades de fãs mais fechadas, mas que no YouTube ganham outra significação já que não há censura ao que é dito sobre a produção da youtuber e sobre os fanworks. Mas, como vimos na observação, não podemos desconsiderar que há um tipo de vivência dentro

Rev.Cad.Comun. Santa Maria, v.21, n.2, art 4, p. 80 de 91, maio/ago.2017 
dessas comunidades virtuais, com trocas importantes, que deixa pouco espaço para um dom unilateral, já que a ausência de vontade de retribuição sinaliza a falta de vontade de ser parte de uma comunidade de fãs. $\mathrm{E}$ é justamente no desejo de retribuição, de compartilhar com outros fãs, como relatado por Karoline, que existem essas associações essenciais para manter um fandom vivo e ativo.

Após assistir os vídeos e ler os comentários no canal de Kéfera de 15 de setembro de 2015 a 15 de dezembro de 2015, foi possível identificar algumas tendências de comportamento preliminares em comum às audiências desses canais:

a) adoradores: parecem ser os fãs mais engajados, que se colocam na disputa por críticas à youtuber, que consideram sempre pessoais, deixam registrada a admiração que sentem pela youtuber, chegam a comentar mais de uma vez por vídeo, divulgam o próprio trabalho de fã;

b) opinativos: sempre deixam registrada sua opinião sobre o conteúdo do vídeo em questão. Não pendem nem para o elogio, nem para as críticas, mas ressaltam o que pensam sobre o assunto, sua opinião é mais importante que a da youtuber;

c) haters: conhecidos e estudados (Lange, 2007, Lange, 2008, Amaral, 2014), entram no canal, assistem aos vídeos sempre para criticar a youtuber e o conteúdo. Normalmente são agressivos nos comentários, que não trazem nenhum tipo de argumentação sobre o desagrado. Também foi possível notar que entram em conflito com os adoradores;

d) autodivulgadores: algumas vezes comentam para elogiar, mas a função deles é divulgar o próprio canal na rede social. Como o YouTube é uma rede unidirecional, ou seja, não possui um elo duplo, basta que alguém se inscreva para receber as informações sem a necessidade da outra pessoa fazer o mesmo, a autodivulgação em canais de grande visibilidade é comum porque traz um retorno em termos de novos inscritos;

Nessa leitura preliminar foi possível notar que os maiores embates acontecem entre os adoradores e os haters. Algumas vezes rendem dezenas de respostas, sempre a partir de um primeiro comentário de um deles,

Rev.Cad.Comun. Santa Maria, v.21, n.2, art 4, p. 81 de 91, maio/ago.2017 
até que uma das partes pare de responder, ou um novo embate comece em um próximo vídeo.

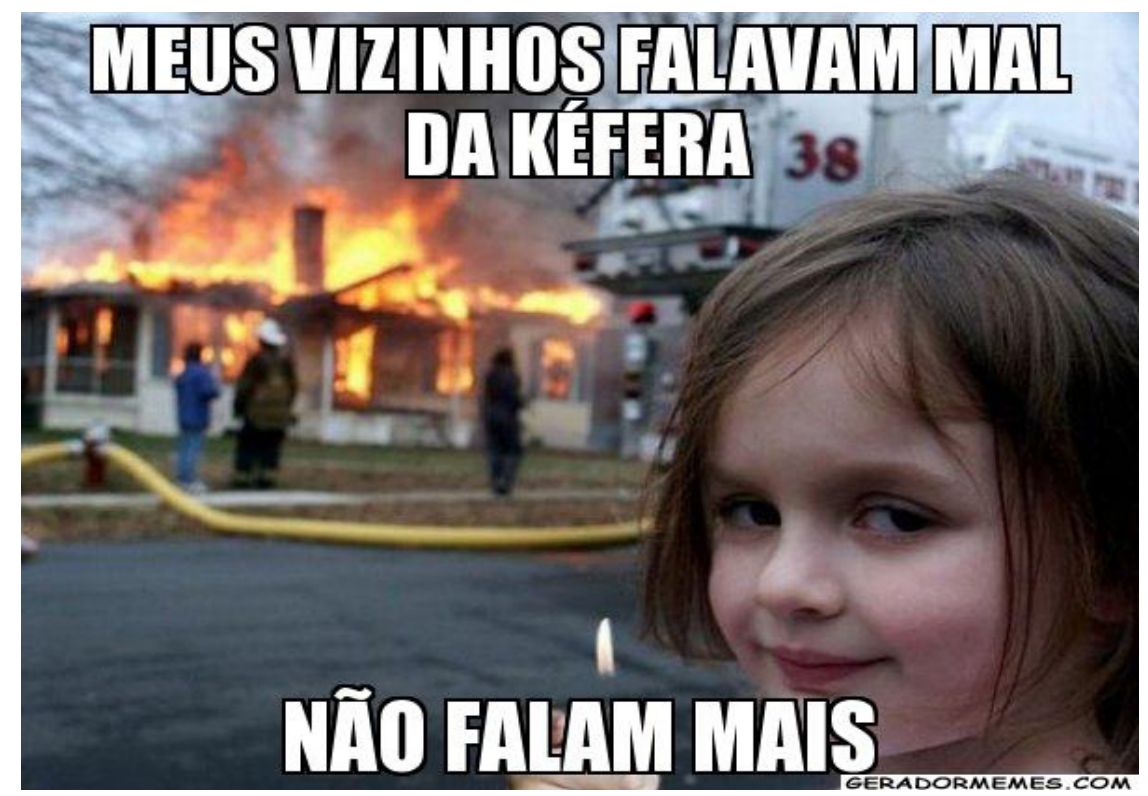

Figura 1. Exemplo de meme produzido por fãs de Kéfera, a partir de um link postado em comentário de um adorador no canal sincominutos

Ao observar os canais 5incominutos e Frases de Kéfera, vemos depoimentos de fãs criticando os haters. Dizem não compreender porque alguém usa seu tempo disponível para assistir algo que não gosta e xingar indiscriminadamente. Existem também disputas entre os próprios fãs sobre a atenção que alguns ganham da própria Kéfera. Em entrevista ao jornal Zero Hora, Karoline Oliveira conta que Kéfera Ihe enviou um vídeo parabenizando-a pelo aniversário e que outras fãs ficam com ciúmes e foram até cruéis ao expressar a inveja: "Já fizeram até montagens maldosas de mim, não entendo" (Oliveira apud Minozzo, 2015, p.24).

Uma das grandes mudanças que ajuda a entender o sucesso dos youtubers é a do consumo midiático dos jovens. Adotamos a noção de consumo midiático de Toaldo e Jacks (2013), que partem do entendimento esboçado por Canclini (1993). Esse entendimento foi importante para a realização de uma pesquisa de âmbito nacional ${ }^{23}$ para compreender o consumo cultural e midiático de jovens brasileiros em tempos de convergência, que já dava pistas sobre o que estamos vendo no contexto do YouTube.

23 A pesquisa Jovem e Consumo Midiático em Tempos de Convergência constitui um estudo, desenvolvido pela Rede Brasil Conectado, sob coordenação da Prof. Dra. Nilda Jacks,e investiga as formas de consumo e apropriação de tecnologias midiáticas por jovens brasileiros de 18 a 24 anos.

Rev.Cad.Comun. Santa Maria, v.21, n.2, art 4, p. 82 de 91, maio/ago.2017 
Além de repositório de vídeos e rede social, virou fonte de entretenimento. Karoline também disse que descartou a televisão como fonte de entretenimento e que Kéfera é mais influentes que atores de novela (Oliveira apud Minozzo, 2015, p.24). Essa mudança que demonstra como a cultura - ou a cibercultura - está transformando e sendo transformada por novos hábitos (e habitus).

\section{A AMBIGUIDADE DO DOM NA COMUNIDADE DE FÃS}

Compreender o universo cultural dos fãs é uma das temáticas centrais dentro do que entendemos por cultura participativa (Jenkins, 2009). Não é incomum que indivíduos se sintam conectados a um produto da indústria cultural - uma canção, filme, livro (ou canais do YouTube) - seja pelas ideias ou histórias que esses dispositivos contam, seja pelo que despertam e são capazes de gerar (Fiske, 1992). Assim, a identificação que acontece a partir dessas conexões pode estimular a criatividade dos sujeitos a ponto de que queiram compartilhar como obra os sentidos e significados dos produtos culturais dos quais são fãs.

Observando as diferentes comunidades de fãs, podemos notar padrões de comportamento igualmente distintos. Cada fã pode ter um tipo de produção específica e já temos vários estudos que, de um lado, classificam o tipo de engajamento do fã a partir da materialização dessa ressignificação (Sandvoss, 2013) - quanto mais produz (de tweets e comentários a fanfictions e fanarts) mais envolvido como fã -, de outro os que dizem que todos os fãs são iguais, o que muda são as dinâmicas de socialização dentro da comunidade de fãs (Hills, 2002). De qualquer forma, temos indivíduos que dedicam parte de tempo e atividades pessoais a aprofundar seus conhecimentos sobre um determinado tema e produzir textos (aqui entendidos como qualquer produção, seja em forma de narrativa literária, imagética ou audiovisual) baseados em obras originais comercializadas que, por diferentes razões, Ihe são significativas.

Como já comentamos, essa produção é entregue a outros fãs e ao ídolo como uma dádiva desinteressada. Karoline, quando começou o canal no YouTube e a conta no Twitter para homenagear Kéfera, o fez pelo simples sentimento de fã, de retribuir a dádiva que sentia ao "receber" cada novo vídeo postado. Assim, é possível entender que essa produção de fãs pode também ser considerada uma mercadoria, mas que não aceita a mediação

Rev.Cad.Comun. Santa Maria, v.21, n.2, art 4, p. 83 de 91, maio/ago.2017 
do dinheiro, pois é, em si mesma, capital simbólico. Uma das características principais de que insere esse tipo de capital em uma economia de trocas simbólicas é por sua dualidade, as "verdades duplas" de que trata Bourdieu (1996b, p.161).

Assim, essa produção se inscreveria, ao mesmo tempo, nessas estruturas objetivas, principalmente pelas comunidades que estabelecem um código de honra próprio não-contratual, que não só regeria sua participação na comunidade de fãs, mas a conduta de seus membros, o comprometimento com a obra e a produção. Essas regras apararecem a todo o momento e a cada novo vídeo postado ao ler os comentários dos fãs. Não responder os haters, não apagar comentários, sempre clicar nos links de outros tipos de fanwork sobre Kéfera, inserir o crédito sobre memes em homenagem à youtuber são alguns desses regulamentos próprios que vimos ao longo da observação. Assim, a dádiva da comunidade de fã gera, por um lado, obrigação, por outro, liberdade. Aqui, mais importante do que falar de interessamento e desinteressamento, como Bourdieu, poderíamos falar da ambiguidade desses dons (Chanial, 2009). Se, concomitantemente, há a generosidade de compartilhar uma produção, há também a necessidade de aceitar que nem todos não só não querem essa dádiva, como podem escrachá-la abertamente, como fazem os haters. Da mesma maneira, a produção intensa se transforma em uma forma de poder dentro da comunidade, principalmente se chamar atenção da youtuber e ganhar reconhecimento em algum vídeo posterior.

Muito se fala nos estudos de fãs o quanto a produção dos trabalhos de fãs faz parte apenas de um capital social da comunidade, que é um tipo de mercadoria que como não tem um valor de troca mercantil. Salienta-se, dentro do entendimento de Bourdieu, que todos aqueles envolvidos no universo da obra e, principalmente, dentro da comunidade de fãs, a produção tem apenas valor simbólico, que serve para estabelecer o status do integrante e o quanto precisa ser produzido para que se conquiste espaço.

Entretanto, o que visualizamos é que essa produção não gera apenas valor simbólico, mas mercantil. De Kosnik (2009), por exemplo, defende que o trabalho de fã - justamente por se considerar um trabalho - deva ter a oportunidade de ser remunerado. A autora se refere, principalmente, à questão da produção de fanfictions, que começavam a ser comercializadas em uma plataforma chamada FanLib, que foi comprada pela Disney e não voltou a circular. A principal razão para o impedimento eram os processos

Rev.Cad.Comun. Santa Maria, v.21, n.2, art 4, p. 84 de 91, maio/ago.2017 
por direitos autorais das obras originais que inspiravam essas fanfictions. Depois, em 2013, surgiu o Kindle Worlds, plataforma da gigante Amazon, que vende fanfiction em formato de e-book. A Amazon fechou contratos de licenciamento com empresas de mídia para garantir seguridade legal para a venda dessa produção de fãs. Assim, além de começar uma espécie de "profissionalização" dos fãs, garante alguma liberdade de produção. De Kosnik (2009, p.168-169) vê, da mesma forma, um problema de gênero quando o assunto é o questionamento sobre a gratuidade do trabalho de fã, já que, defende ela, a maior parte da produção de fanfictions é feita por mulheres.

Outro exemplo que temos é o do canal Frases de Kéfera. Ao criar um canal que gera tráfego e visualizações, ela própria, a exemplo do mesmo modelo de negócios que garante a Kéfera os rendimentos na casa dos seis dígitos, passa a receber pelo seu trabalho de fã. Na entrevista ao jornal, ela não revela quanto recebe do YouTube. Não é incomum vermos jovens falando de seu desejo de começarem canais próprios no YouTube para complementar a renda, ou, até mesmo, transformar essa em uma atividade principal. Entretanto, quando a fã criou o canal em homenagem à Kéfera, não era essa a sua intenção.

Dentro das comunidades que produzem fanfictions, os questionamentos sobre a validade do trabalho partem de advogados de empresas detentoras dos direitos desses produtos midiáticos. Dentro do fandom do YouTube, o questionamento sobre a validade do dom parte de outros fãs dentro da caixa de comentários dos vídeos. Vimos, também, comentários em que Karoline é questionada se permanece como fã de Kéfera, já que recebe por um fanwork, que no entendimento da comunidade, deveria ter apenas valor simbólico. A menina se defende apelando para a intencionalidade, já que não era essa a intenção, ela não só acredita e defende que é uma fã fervorosa de Kéfera. Da mesma forma, a remuneração pode ser interpretada como um tipo de dádiva - quase num sentido sagrado - que recebe justamente pelo reconhecimento do próprio desinteressamento na retribuição financeira.

Com esse exemplo, podemos visualizar não apenas como o dom circula dentro dessa comunidade de fãs, mas todas as formas complexas que o próprio dom assume dentro dessas comunidades. Ele aparece dentro dos registros de interessamento e desinteressamento, como característica de alguém “especial”, como elo, como presente/reconhecimento, um víncu-

Rev.Cad.Comun. Santa Maria, v.21, n.2, art 4, p. 85 de 91, maio/ago.2017 
lo que tem contido benevolência e reciprocidade; também é uma forma de capital simbólico e social. Os dons dentro dessa comunidade de fãs não são apenas dados, mas compartilhados. Não com apenas uma pessoa, no caso a youtuber de adoração, mas com muitos outros que fazem parte dos mesmos sites de redes sociais, sejam eles fãs ou não.

\section{CONSIDERAÇÕES FINAIS}

Não temos a pretensão de trazer aqui conclusões definitivas, ou encerrar as discussões sobre a economia da dádiva dentro das comunidades de fãs. O que nos propomos até aqui é a refletir sobre aspectos e práticas que parecem, senão únicos, particulares ao fandom de youtubers. Da mesma forma, nossa contribuição vem da reflexão sobre quais os sentidos que o dom adquire nessas comunidades.

Entendemos que o YouTube, como site de rede social, apresentou novas dinâmicas de interação e que foi, para além das utilidades que foi planejado, ressignificado pelos sujeitos que fazem parte dessa rede social e que atribuem a si o status de comunidade. Da mesma forma, diferente de outras plataformas desenvolvidas no ciberespaço, o YouTube foi apropriado por mulheres, que são maioria hoje no uso e que interagem e produzem conteúdo com mais frequência dentro da ferramenta. E dentro dessa ambiência, também são elas que lidam com a maior parte dos haters.

Por meio da observação do canal 5 incominutos, conseguimos identificar alguns dos sentidos que o dom adquire através das práticas dos fãs de Kéfera Buchmann. Da mesma forma, observamos um canal produzido por uma fã para termos mais pistas sobre a centralidade do dom dentro das dinâmicas dos fãs de Kéfera.

Tentamos aqui mostrar a polissemia do dom através dessas mesmas dinâmicas. Ao trazer fãs e youtuber como personagens, conseguimos ver a manifestação desses sentidos através das disputas que acontecem, não só no fandom de Kéfera, mas em outras esferas dos estudos de fãs. Também conseguimos ver que a economia da dádiva do fandom está sofrendo influências de lógicas comerciais. Hoje vemos fãs que comercializam criações e empresas que passaram a investir em táticas de monetização desses produtos. O YouTube, nesse sentido, também é uma dessas ferramentas. Existem muitos canais especializados, com conteúdo dedicado a games e outras narrativas que mobilizam fãs do mundo inteiro, que tam-

Rev.Cad.Comun. Santa Maria, v.21, n.2, art 4, p. 86 de 91, maio/ago.2017 
bém lucram com o conteúdo de fã. Porém, ao mostrar o YouTube como espaço de surgimento de um fandom específico, de uma personagem que nasce completamente desvinculada da indústria cultural e passa, depois que essa indústria reconhece seus fãs, a fazer parte dela, e esse fandom também se manifesta (e lucra) da mesma ambiência, identificamos uma nova dinâmica de fãs e de circulação de dons.

Seria interessante, para um próximo momento, a fim de avançar nesse assunto, começar a refletir sobre o que, dentro desse fandom, pode ser considerado participação. Como destacamos, os dons compartilhados nesses sites de rede social, diferente das comunidades que são fechadas, trazem consigo a característica da propagabilidade (Jenkins, 2014). Ao fazer isso, poderíamos discutir não só as produções de fã que acontecem a partir das produções de fã (fanwork sobre fanwork), mas analisar a circulação desses dons e como eles se modificam em fãs que apenas recebem esses dons, mas se identificam como fãs. Hills (2002, p.30) argumenta que há uma supervalorização da produção dentro dos estudos de fãs e que nem todos eles produzem, o que não diminuiria a identificação e ressiginificação das obras. Esses fãs, da mesma forma, consomem esses dons e possuem um papel preponderante para a circulação da produção de trabalhos de fãs.

Com isso, podemos ver o quanto a questão do dom e das sociabilidades que suscita são complexas. E que, apesar do quase centenário do trabalho que deu luz a esse conceito, está longe de ter seus sentidos esgotados. Da mesma forma, se une às práticas sociais e se transformam e ressignificam, como o caso das comunidades de fãs, que sempre existiram, mas que conforme surgem novas possibilidades de relações, elos e ídolos a serem adorados, evoluem em formato e modificam suas práticas. 
CADERNOS DE COMUNICAÇÃO

UNIVERSIDADE FEDERAL DE SANTA MARIA

REFERÊNCIAS

ANGROSINO, Michael. Etnografia e observação participante. Porto Alegre: Artmed, 2009.

BOURDIEU, Pierre. “É possível um ato desinteressado?" In: Razões Práticas. Campinas, Papirus, 1996, p. 137-61.

. “A economia dos bens simbólicos". In: Razões Práticas. Campinas, Papirus, 1996b, p. 163-203.

BRAGA, Adriana. Técnica etnográfica aplicada à comunicação on- line: uma discussão metodológica. UNIrevista - Vol. 1, n³: (julho 2006).

BURGESS, J., GREEN, J. YouTube e a revolução digital: como o maior fenômeno da cultura participativa transformou a mídia e a sociedade. São Paulo: Aleph, 2009.

. Agency and controversy in the YouTube Community. In: Internet Research 9.0: Rethinking Community, Rethinking Place, 2008. Universidade de Copenhague, Dinamarca.

CAILLÉ, Alain. O dom entre interesse e desinteressamento. In: MARTINS, Paulo Henrique e CAMPOS, Roberta Bivar (org.). Polifonia do Dom. Ed. Universitária UFPE, 2006.

CANCLINI, Nestor Garcia. El consumo cultural en México. México: Grijalbo, 1993.

CHANIAL, Philippe. Ce que le donner donne a voir: esquisse d'une grammaire des relations humaines en cle de don. In: Mauss Vivant. Séminaire international, 13-20 Juin 2009, Cerisy-la-Salle, p.31-61.

Rev.Cad.Comun. Santa Maria, v.21, n.2, art 4, p. 88 de 91, maio/ago.2017 
DAMO, Arlei. Do dom à profissão. São Paulo: HUCITEC, 2007.

DE KOSNIK, Abigail. Should Fan Fiction Be Free? Cinema Journal, [s.I.], v. 48, n. 4, p. 118-124, 2009.

FISKE, John. "The cultural economy of fandom" in LEWIS, Lisa .A. (ed.) The adoring audience: fan culture and popular media. New York: Routledge, 1992.

FRAGOSO; Suely; RECUERO, Raquel; AMARAL, Adriana. Métodos de pesquisa para internet. Porto Alegre: Sulina, 2011.

GODBOUT, Jacques. "Homo donator versus homo oeconomicus". In: Paulo Henrique Martins (org.). A dádiva entre os modernos. Discussão sobre os fundamentos e as regras sociais. Petrópolis, Vozes, 2002, p. 6397.

HILL, Matt. Fan Cultures. London: Routledge, 2002.

HINE, Christine. Etnografia Virtual. Barcelona, Espana: UOC, 2004.

JACKS, Nilda. TOALDO, Mariângela. SCHMITZ, Daniela. MAZER, Dulce. WOTTRICH, Laura. da COSTA, Sarah. Jovem brasileiro e consumo midiático em tempos de convergência: panorama preliminar. In: XII Congreso ALAIC - Asociación Latinoamericana de Investigadores en Comunicación. Lima: PUCP, 2014.

JENKINS, Henry. Cultura da convergência. São Paulo: Aleph, 2009. . Cultura da Conexão: criando valor e significado por meio da 
CADERNOS DE COMUNICAÇÃO

UNIVERSIDADE FEDERAL DE SANTA MARIA

mídia propagável. São Paulo: Aleph, 2014.

LANGE, Patricia. Commenting on Comments: Investigating Responses to Antagonismo on YouTube. Society for Applied Anthropology Conference, 2007. Florida, Estados Unidos.

. Publicly Private and Privately Public: Social Networking on YouTube. Journal of Computer-Mediated Communication 13. Dezembro, 2007, p.361-380.

MAUSS, Marcel. Sociologia e Antropologia. São Paulo, Cosac Naify, 2003.

MINOZZO, P. Eles são youtubers. Caderno Sua Vida, Jornal Zero Hora, Porto Alegre, 2015, p.23-25.

MOLYNEAUX, H., O'DONNELL, S., GIBSON, K., SINGER, J. Exploring the Gender Divide on YouTube: An Analysis of the Creation and Reception of Vlogs. American Communication Journal. Volume 10, Number 2. Summer 2008.

PRIMO, Alex. Interney Blogs como micromídia digital: Elementos para o estudo do encadeamento midiático. In: $17^{\circ}$ Encontro Anual de Associação Nacional dos Programas de Pós-Graduação em Comunicação, 2008, São Paulo. Anais... , 2008. p.1-17.

SANDVOS, Cornel. Quando estrutura e agência se encontram: os fãs e o poder. Ciberlegenda, Rio de Janeiro, v. 1, n. 28, p. 8-41, 2013.

SENFT, Theresa. Camgirls: celebrity and community in the age of social networks. Nova York: Peter Lang Publishing, 2008.

STRANGELOVE, Michael. Watching YouTube: extraordinary vídeos by Rev.Cad.Comun. Santa Maria, v.21, n.2, art 4, p. 90 de 91, maio/ago.2017 
oridnary people. Toronto:UTP, 2011.

SZOSTAK, Natasha. Girls on YouTube: Gender Politics and the Potential for a Public Sphere. The McMaster Journal of Communication Volume 8, 2013. Hamilton, Canadá.

TOALDO, M.; JACKS, N. A. Consumo midiático: uma especificidade do consumo cultural, uma antessala para os estudos de recepção. In: Encontro Anual da Associação Nacional de Programas de Pós-Graduação em Comunicação, 22, 2013, Salvador, BA. Anais, Salvador: UFBA.

\section{Paula Coruja}

Mestre em Comunicação e Informação (PPGCOM/UFRGS), integrante do Grupo de Pesquisa Cultura e Recepção Midiática. Especialista em Administração e Marketing e jornalista formada pela Unisinos.

E-mail: paula.coruja@gmail.com

RECEBIDO EM: 27/07/2016

ACEITO EM: 27/09/2016 